\title{
Reduction of corneal sensitivity after retinal detachment surgery
}

\author{
R. A. GIBSON \\ From the Bristol Eye Hospital, Bristol
}

SUMMARY Corneal sensitivity measurements were performed on both eyes of 57 patients after they were subjected to unilateral retinal detachment surgery, the unoperated eyes acting as controls. A marked decrease in corneal sensitivity was found in eyes that were treated with encircling bands, but no significant change of sensitivity could be detected in eyes in which localised radial or circumferential silicone sponge explants alone had been employed. It would appear that encirclement procedures lower the sensitivity of the cornea, and this may continue as a long-term effect.

Sensory impulses from the cornea are conducted in the long and short ciliary nerves which lie in the suprachoroidal space prior to piercing the sclera at the posterior pole of the eyeball. ' While in the suprachoroidal space the ciliary nerves are potentially vulnerable to the trauma, both thermal and mechanical. which is deliberately applied as part of the surgical therapy for rhegmatogenous retinal detachments. There is evidence from both experimental ${ }^{2}$ and human studies ${ }^{3}$ that cooling of nervous tissue may interfere with impulse conduction. However, there is little published information about the effects on ciliary nerve function of mechanically distorting the choroid by the explants used in retinal detachment surgery.

To determine whether corneal sensitivity does indeed become impaired following retinal detachment surgery a study was instituted in which corneal sensation was recorded with the Cochet-Bonnet corneal aesthesiometer ${ }^{4-6}$ in patients who had undergone previous unilateral retinal detachment surgery.

\section{Materials and methods}

Patients who had undergone strictly unilateral retinal detachment surgery in the Bristol Eye Hospital during a 2-year period from January 1978 to December 1979 were recalled for corneal sensitivity measurements in each eye. The unoperated contralateral fellow eye in which no surgical procedures whatsoever, including light coagulation and cryotherapy, had been per-

Correspondence to R. A. Gibson. FRCSEd. Bristol Eve Hospital. Lower Maudlin Street, Bristol BS1 2LX. formed acted as a control. Factors which included variations between individuals, humidity, age, ${ }^{7}$ menstruation, ${ }^{8}$ pregnancy, ${ }^{9}$ and diurnal variation of sensitivity ${ }^{10}$ could therefore be neglected.

To avoid observer bias" the type of retinal detachment procedure was not known to the examiner until after corneal sensitivity measurements had been determined.

The patients were seated at a slit-lamp, and the fellow eye was stabilised with the fixation light attachment of the slit-lamp. Under a $\times 12.5$ magnification the nylon filament of a hand-held aesthesiometer was applied at a slow. constant speed to the cornea at right-angles to this tissue's surface until the filament was seen to just bend. All studies began with the filament extended to its longest length of $6 \mathrm{~cm}$ and subsequently retracted by centimetre decrements until at each point tested $50 \%$ of the touches were reported by the subject. Each corneal point was touched 4-6 times with at least one blank to test the subject's reliability. Five corneal points were stimulated. ${ }^{12}$ first at the corneal centre and then midway between centre and limbus at the 6.9.3. and 12 o'clock positions on the cornea; the sensitivity measurements were plotted on charts as shown in Fig. 1.

The total score for an eye was obtained by adding the numbers in each quadrant together. These scores were tabulated, the means, standard deviations, and probabilities calculated, and the measurements of the operated eves compared with those of the fellow control eves. Changes in corneal sensitivity were calculated by subtracting the score of an operated eve from that of its fellow eve and plotting the result 
CHART USED TO RECORD RESULTS
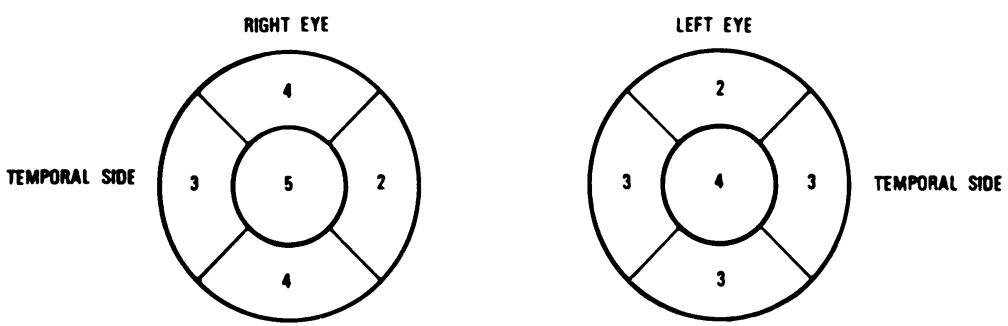

Fig. 1 Chart used to record results.

vertically as a decrease or increase in corneal sensitivity.

\section{Results}

Measurements were carried out on 57 pairs of eyes of patients whose ages ranged from 14 to 80 years of age, with a mean age of 52 .

Unilateral encirclement procedures were performed on 27 patients and localised plombage on 30 patients. In the latter group, 7 had local radial plombage, 19 had circumferential plombage involving no more than 2 quadrants, and in 4 cases radial and circumferential plombage were combined. Anatomical reapposition of the retina had been achieved in 52 out of the 57 cases, a success rate of $91 \%$. The 5 failures (cases A-E) are indicated in Fig. 2.

Graphical representation of the pooled results in Fig. 2 indicates that of the 57 pairs of eyes tested, 42 pairs $(73.7 \%)$ showed a decrease in sensitivity of the operated eye, and 8 pairs (14\%) showed no change. In 7 pairs $(12.3 \%)$ the sensitivity of the operated eve appeared to be increased, but, as this increase in sensitivity lay within a single standard deviation of the values obtained for corneal sensitivity of the control unoperated eyes, these fell within the normal range for such measurements.

Although the pooled results show that corneal sensitivity is reduced in operated eyes and that this reduction appears to be statistically significant

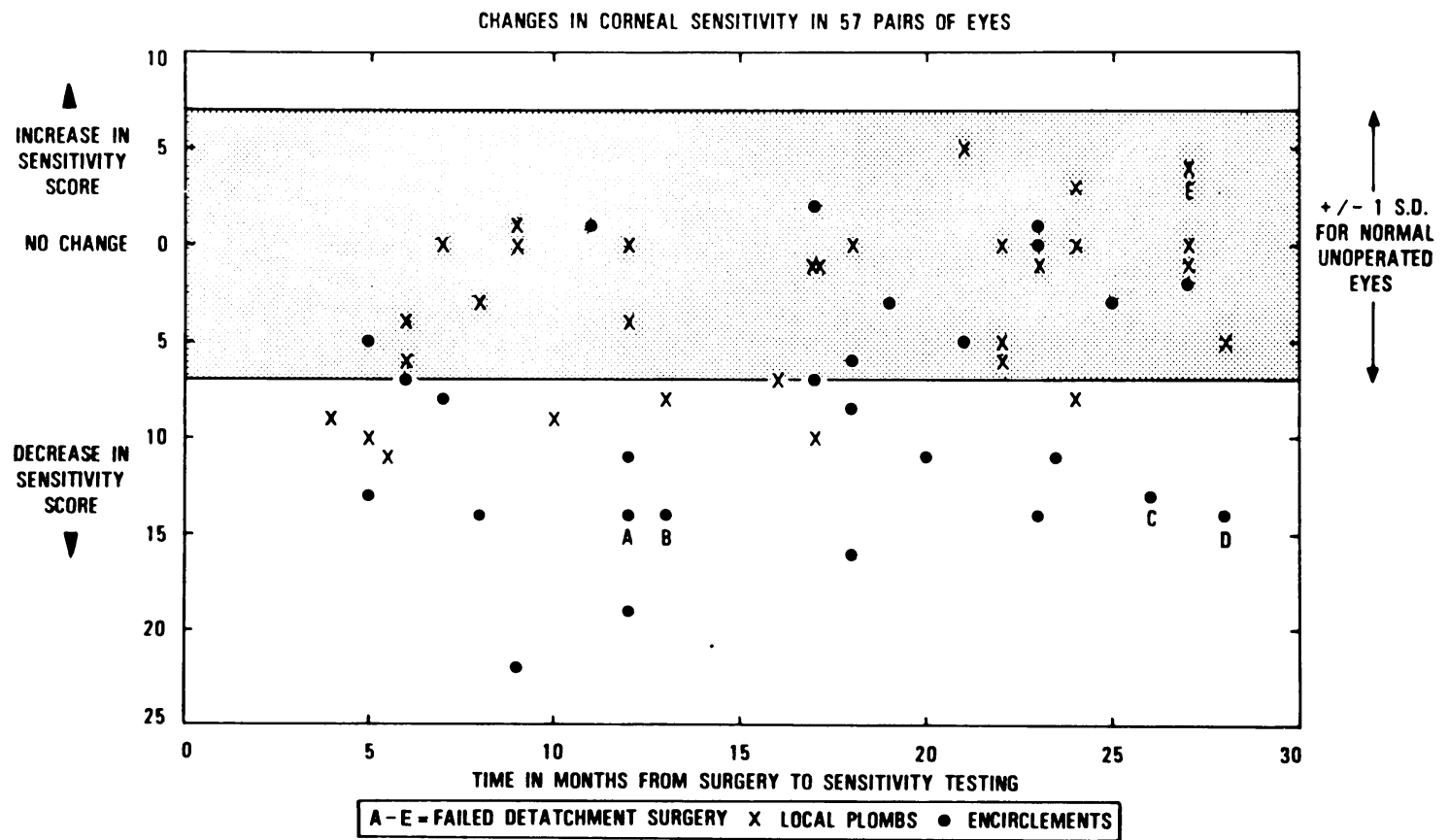

Fig. 2 Changes in corneal sensitivity in 57 pairs of eyes. 
$(t=3.97, \mathrm{p}<0.001$, Table 1), further analysis of the pooled results showed that it was those patients who had undergone encirclement procedures who were responsible for the weighting of the group as a whole. The diminution in corneal sensitivity of the 27 encircled eyes is highly significant $(t=3.90, \mathrm{p}<0.001$, Table 2), whereas the disturbance in corneal sensation in the other 30 pairs of eyes was not statistically significant.

No significant decrease in sensation was recorded in 7 patients in whom a single quadrant radial plomb was employed for explant indentation (Table 3) or in 19 cases in which a circumferential plomb of less than one-half ocular circumference was utilised (Table 4). Even when the sensitivity scores of corneal quadrants immediately adjacent to the local explants are considered (Table 5), the localised diminution in corneal sensation of 30 operated eyes did not prove to be statistically significant.

Table 1 Overall corneal sensitivity in 57 pairs of eyes

\begin{tabular}{|c|c|c|c|}
\hline & Mean & $S D$ & \\
\hline $\begin{array}{l}\text { Operated eyes } \\
\text { Fellow eyes }\end{array}$ & $\begin{array}{l}15.05 \\
20.78\end{array}$ & $\begin{array}{l}8.29 \\
7.06\end{array}$ & $t=3.97 \mathrm{p}<0.001$ \\
\hline
\end{tabular}

Table 2 Corneal sensitivity in 27 encircled eyes

\begin{tabular}{|c|c|c|c|}
\hline & Mean & $S D$ & \\
\hline $\begin{array}{l}\text { Operated eyes } \\
\text { Fellow eves }\end{array}$ & $\begin{array}{l}12 \cdot 25 \\
20 \cdot 77\end{array}$ & $\begin{array}{l}8 \cdot 62 \\
7 \cdot 44\end{array}$ & $t=3.90 \quad \mathrm{p}<0.001$ \\
\hline
\end{tabular}

Table 3 Corneal sensitivity in 7 eyes with single quadrant radial plombs

\begin{tabular}{lllll}
\hline & Mean & $S D$ & \\
\hline Operated eyes & 17.57 & 5.80 & $t=1.45$ & $\mathrm{p}<0.5$ \\
Fellow eyes & 21.42 & 3.91 & & \\
\hline
\end{tabular}

Table 4 Corneal sensitivity in 19 eyes with circumferential plombs up to half ocular circumference

\begin{tabular}{lllll}
\hline & Mean & $S D$ & \\
\hline Operated eyes & 18.31 & 7.99 & $t=1.02$ & $\mathrm{p}<0.5$ \\
Fellow eyes & 20.84 & 7.24 & & \\
\hline
\end{tabular}

Table 5 Corneal sensitivity in 30 eyes with radial or circumferential or combined plombs-totalling adjacent peripheral quadrant scores only

\begin{tabular}{lllll}
\hline & Mean & $S D$ & \\
\hline Operated eyes & 5.56 & 4.09 & $t=1.147 \quad \mathrm{p}<0.5$ \\
Fellow eyes & 6.76 & 4.00 & & \\
\hline
\end{tabular}

\section{Discussion}

It is thought that a single nerve trunk entering the limbus of the cornea may supply up to $25 \%$ of the corneal surface. As Rexed and Rexed ${ }^{13}$ have shown that sensation in the rabbit cornea is lost only immediately adjacent to a full-thickness incision through this tissue, it would appear reasonable to expect therefore that procedures which could potentially damage the ciliary nerves over $360^{\circ}$ of the ocular circumference might be more likely to produce a measureable change in corneal sensation than more localised surgery. This was found to be the case in the present study, with encirclement procedures producing a highly significant reduction in corneal sensitivity, while the diminution in sensitivity produced by local explants alone was not so significant.

As the degree, extent, and duration of cryotherapy were not sufficiently well annotated in many of the case records, it has not been possible in this study to analyse retrospectively the individual contributions of retinal cryopexy and mechanical scleral indentation in disturbing ciliary nerve function. Nevertheless, previous animal and human studies on freezing peripheral nerves ${ }^{23}$ have indicated that sensory conduction defects are usually transient, so it would appear likely that the mechanical effects of indentation might well be of greater importance for longterm impairment of ciliary nerve function.

Although a reduction of corneal sensation might appear of little importance compared to the complications of overenthusiastic scleral indentation, ${ }^{14}$ namely, anterior segment ischaemia and 'strap pain,' it does need to be added to the list of disturbances producing corneal hypoaesthesia. The significance of a finding of diminished corneal sensation needs critical evaluation, therefore, if an eye has undergone previous retinal detachment surgery.

My thanks are due to Professor M. Millodot for helpful advice and to Mr J. C. D. Hart for reading the paper. The consultant staff of the Bristol Eye Hospital are thanked for allowing me to study patients under their care.

\section{References}

1 Wolff E. Anatomy of the Eye and Orbit. 7th ed. Revised by Warwick R. London: H.K. Lewis, 1976: 47-8.

2 Denny-Brown D, Adams RD, Brenner C, Doherty MM. Pathology of injury of nerve induced by cold. J Neuropathol Exp Neurol 1945; 4: 305-23.

3 Lloyd JW, Barnard JDW, Glynn CJ. Cryoanalgesia, a new approach to pain relief. Lancet 1976; ii: 932-4.

4 Boberg-Ans J. Experience in clinical examination of corneal sensitivity. Br J Ophthalmol 1955; 39: 705-26.

5 Millodot M. Objective measurement of corneal sensitivity. Acta Ophthalmol (Kbh) 1973; 51: 325-34.

6 Cochet P, Bonnet R. L'esthésie cornéenne. Clinique Ophtalmologique 1960; 4: 3-27. 
7 Millodot $M$. The influence of age on the sensitivity of the cornea. Invest Ophthalmol Visual Sci 1977; 16: 240-22.

8 Millodot M. Lamont A. Influence of menstruation on corneal sensitivity. Br J Ophthalmol 1974: 58: 752-6.

9 Millodot $M$. The influence of pregnancy on the sensitivity of the cornea. Br J Ophthalmol 1977; 61: 646-9.

10 Millodot M. Diurnal variation of corneal sensitivity. $\mathrm{Br} J$ Ophthalmol 1972: 56: 844-7.
11 Gibson RA. Sanderson HF. Observer variation in ophthalmology. Br J Ophthalmol 1980; 64: 457-60.

12 Lyne AJ. Corneal sensation in scleritis and episcleritis. $\mathrm{Br} \mathrm{J}$ Ophthalmol 1977; 61: 650-4.

13 Rexed B. Rexed U. Degeneration and regeneration of corneal nerves. Br J Ophthalmol 1951; 35: 38-49.

14 Lincoff H. Kreissig I, Parner L. Limits of constriction in the treatment of retinal detachment. Arch Ophthalmol 1976; 94: 1473-7. 